\title{
Exposure to vinyl chloride monomer: report on a cohort study
}

\author{
AGNÈS LAPLANCHE, ${ }^{1}$ FRANÇOISE CLAVEL, ${ }^{2}$ J-C CONTASSOT, 3 \\ GLAUDINE LANOUZIERE
}

From the Département de Statistique Médicale, ${ }^{1}$ and Unité de Recherche 287 INSERM, ${ }^{2}$ Institut Gustave Roussy, 94805 Villejuif, Atochem, ${ }^{3} 69190$ St Fons, and Solvay et Cie, ${ }^{4} 39500$ Tavaux, France

\begin{abstract}
In 1980 a prospective exposed/non-exposed cohort study was initiated in France by the Institut National de la Santé et de la Recherche Médicale (INSERM U 287) to evaluate the association between mortality and cancer morbidity and occupational exposure to vinyl chloride monomer (VCM). Eleven hundred VCM exposed subjects and 1100 VCM non-exposed controls matched for age $( \pm 2$ years), plant, and physician were included and followed up over a five year period for vital, health, and occupational status. The percentages of deaths observed among the exposed $(1.8 \%)$ and non-exposed subjects $(1.6 \%)$ did not differ. Eighteen $(1.6 \%)$ and $15(1.4 \%)$ cases of cancer were reported among exposed and non-exposed subjects, respectively (NS). One case of angiosarcoma of the liver occurred among the exposed group; six cases of lung cancer occurred among exposed subjects and two among non-exposed subjects (NS). The percentage of diseases of the circulatory system was higher $(p<0.02)$ in the exposed group than in the non-exposed group: this difference was explained mainly by the high incidence of Raynaud's disease $(p<0.006)$. The percentages of diseases of the respiratory system did not differ between the two groups.
\end{abstract}

Several epidemiological studies of subjects occupationally exposed to vinyl chloride monomer (VCM) have been conducted. ${ }^{1-19}$ Although these studies differ in size and design, and cover different periods, they all conclude that the risk of some diseases, angiosarcoma of the liver (ASL) and acrosteolysis, for example, is increased by exposure to VCM. In 1980 a prospective exposed/non-exposed cohort study was initiated by the Institut National de la Santé et de la Recherche Médicale (INSERM U 287 ) in France. The main purpose of this study was to evaluate the association between mortality and morbidity (especially from malignant tumours) and occupational exposure to VCM.

\section{Materials and methods}

The present study included most of the French VCM polymerisation plants. The exposed group consisted of 40-55 year old employees, either presently exposed or having been exposed to VCM. Foreigners were

Accepted 13 October 1986 included if they had been living in France with their family for at least five years. Controls were employees never exposed to VCM. Each control was matched to one exposed subject for age $( \pm 2$ years), plant, and physician. Interviews for initial data collection were conducted by each plant physician over a year. Data collected included identification, employment history (the entire work history was coded), occupational category, and amount of exposure to VCM (defined for polymerisation functions as low since 1976, moderate between 1970 and 1976, and high before 1970), and medical history in addition to smoking and drinking habits. Each year until December 1985 the subjects were followed up for vital, health, and occupational status. Causes of death and specific abnormalities were coded according to the International Classification of Diseases (ICD, 9th revision). Subjects who had terminated their employment (resigned, transferred, or retired) were followed up by each physician by post.

The data were analysed using the PIGAS system. ${ }^{20}$ Control for confounding factors, such as cigarette smoking, alcohol consumption, and socioeconomic status, was performed using the Mantel-Haenszel procedure. ${ }^{21}$ 
Table 1 Distribution of subjects by plant

\begin{tabular}{lc}
\hline & No of subjects (\%) \\
\hline Tavaux (Solvay) & $886(40)$ \\
Saint-Fons (Atochem) & $656(30)$ \\
Roussillon (Rhone-Poulenc) & $170(8)$ \\
Aubervilliers (Rhone-Poulenc) & $124(6)$ \\
Lavera (Atochem) & $110(5)$ \\
Saint-Auban (Atochem) & $84(4)$ \\
Bully-les-Mines (CDF Chimie) & $70(3)$ \\
Ribecourt (Rhone-Poulenc) & $30(1)$ \\
Port-de-Bouc (Atochem) & $22(1)$ \\
Commentry (AEC Rhone-Poulenc) & $18(1)$ \\
Montluel (Atochem) & $18(1)$ \\
Antony (Rhone-Poulenc) & $12(1)$ \\
Total & 2200 \\
\hline
\end{tabular}

\section{Results}

From June 1980 to May 1981, 2200 employees were included: 1100 exposed and 1100 controls in 12 plants (table 1). Two plants recorded over $70 \%$ of the entire cohort.

\section{DESCRIPTION OF THE CHAR ACTERISTICS OF THE}

\section{COHORT}

Most initial characteristics, smoking, and drinking habits did not differ among exposed and non-exposed subjects (table 2).

A socioeconomic characteristic was defined.
Laplanche, Clavel, Contassot, Lanouziere

Employees whose occupational activity was coded aš worker for more than $75 \%$ of their entire work history were considered as blue collar workers; the remainder were classified as white collar workers $\overrightarrow{\overline{\vec{\varphi}}}$ These percentages did not differ between the two groups.

\section{DESCRIPTION OF EXPOSURE TO VCM}

At the time of the interview, only $36 \%$ of the exposed? group was exposed to VCM, the rest having beenes exposed in the past. They represented the following occupations: CV synthesis $(17 \%)$, polymerisation(54\%), copolymerisation $(7 \%)$, and compoundagew and pharmacy $(22 \%)$. The mean $( \pm S D)$ totas duration of exposure to VCM was 14 years $( \pm 8)$ and $\frac{\mathbb{D}}{3}$ the mean time between the first exposure and interview was 18 years $( \pm 8)$. The amount of exposure hav $\rightarrow$ ing been coded as low, moderate, or high, there weree seven different combinations of exposure level during $\lambda$ the entire work history of exposed employees. Table 3 shows the distribution of exposed subjects according to these combinations, the mean exposure duration at each level, and the time between the first exposure and the interview.

\section{FOLLOW UP OF THE COHORT}

The follow up of the two groups was similar. By $1985, \overline{\mathscr{C}}$ $15 \%$ of the subjects initially included had retired, $28 \%$ had resigned or been transferred, and $4 \%$ were no sick leave. The percentage of subjects lost to follow $\underline{\mathrm{p} p}$

Table 2 Initial characteristics of exposed and control groups

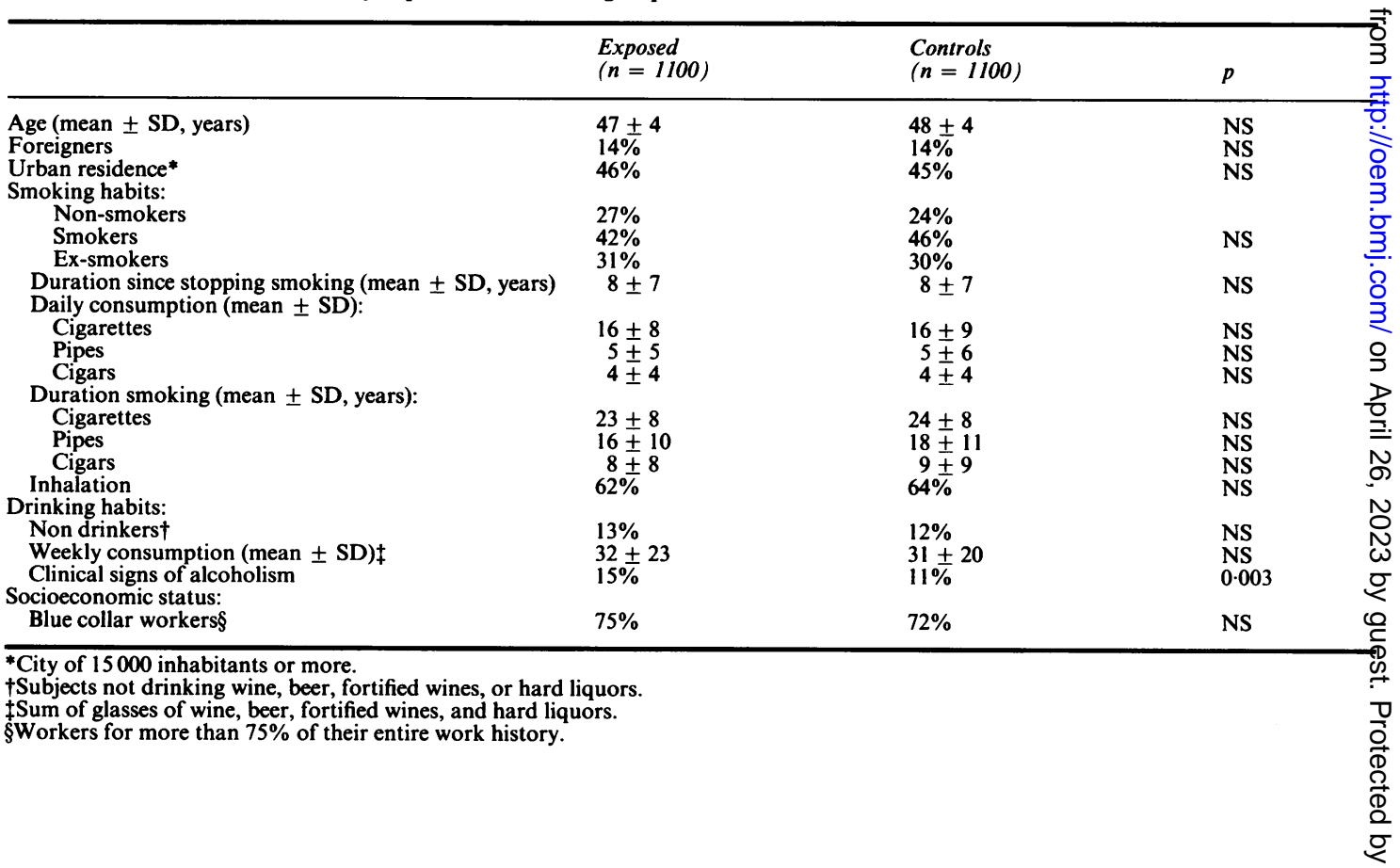


Table 3 Distribution of exposed subjects according to levels of exposure to VCM

\begin{tabular}{|c|c|c|c|}
\hline Level* & $\%$ & $\begin{array}{l}\text { Duration of exposure* } \\
\text { mean } \pm S D \text { (years) }\end{array}$ & $\begin{array}{l}\text { Time between } \\
\text { lst exposure and interview mean } \pm \text { (years) }\end{array}$ \\
\hline \multirow{5}{*}{$\begin{array}{l}1 \\
2 \\
3 \\
1+2\end{array}$} & \multirow{5}{*}{$\begin{array}{r}37 \\
13 \\
8 \\
14\end{array}$} & \multirow{5}{*}{$\begin{array}{l}D=D 1=11 \pm 7 \\
D=D 2=9 \pm 8 \\
D=D 3=9 \pm 7 \\
D=16 \pm 7 \\
D 1=8 \pm 5 \\
D 2=8 \pm 6\end{array}$} & $14 \pm 8$ \\
\hline & & & $17 \pm 7$ \\
\hline & & & $18 \pm 8$ \\
\hline & & & $10+6$ \\
\hline & & & $19 \pm 0$ \\
\hline $1+3$ & 10 & $\begin{array}{l}D=18 \pm 8 \\
D 1=10 \pm 7 \\
D 3=8 \pm 6\end{array}$ & $22 \pm 7$ \\
\hline $2+3$ & 3 & $\begin{array}{l}D=20 \pm 9 \\
D 2=11 \pm 7 \\
D 3=9 \pm 6\end{array}$ & $24 \pm 7$ \\
\hline $1+2+3$ & 16 & $\begin{array}{l}\mathrm{D}=21 \pm 4 \\
\mathrm{D} 1=7 \pm 3 \\
\mathrm{D} 2=7 \pm 4 \\
\mathrm{D} 3=6 \pm 5\end{array}$ & $22 \pm 5$ \\
\hline
\end{tabular}

${ }^{*} 1$ = Low; 2 = moderate; 3 = high.

$+D=$ Total exposure duration; $D 1=$ level 1 exposure duration; $D 2=$ level 2 exposure duration; $D 3=$ level 3 exposure duration.

during the five years-that is, whose vital and health status was unknown-was $3 \%$. These percentages did not differ between exposed and non-exposed groups (table 4).

\section{MORTALITY OF THE COHORT}

During the five year follow up period, $20(1.8 \%)$ exposed and $17(1.6 \%)$ non-exposed subjects died. These percentages did not differ significantly. Table 5 shows the causes of death.

\section{MORBIDITY OF THE COHORT}

During the five year follow up period, $18(1.6 \%)$ and $15(1.4 \%)$ cases of cancer were reported among exposed and non-exposed subjects, respectively. These percentages did not differ significantly. The distribution of cancer sites is presented in table 6 . One case of angiosarcoma of the liver occurred among the exposed group. Eight cases of lung cancer were reported, six among the exposed subjects $(0.5 \%)$ and only two among the non-exposed subjects $(0.2 \%)$; the percentages of lung cancer did not differ between the two groups. The percentage of diseases of the circulatory system (ICD: $390-459)$ was higher $(p<0.02)$ among the exposed group (10\%) than among the control group (7\%) (table 7). Six categories were considered: hypertension, coronary insufficiency, cerebrovascular disease, arteriosclerosis of the limbs,
Raynaud's disease, and other vascular diseases. The only association found concerned Raynaud's disease, and other vascular diseases. The only association found concerned Raynaud's disease ( $p<0.007)$.

The percentage of diseases of the respiratory system (ICD: 460-519) did not differ between the two groups and no case of pulmonary fibrosis was recorded. These results were not materially altered by adjustment for tobacco smoking, alcohol status, and socioeconomic category.

\section{Discussion}

Subjects were included in the study if they were under 55 in order to allow a five year minimal follow up without too many withdrawals, as retirement usually takes place around age 55-60. Moreover, the subjects had to be over $\mathbf{4 0}$ for two reasons: firstly, to include only subjects who had been exposed to VCM for a sufficiently long time when levels of exposure were appreciably higher than at present and, secondly, because the incidence of malignant disease increases with age.

Considering the percentage of retired, resigned, or transferred subjects, the percentage of subjects lost to follow up $(3 \%)$ is low. This results from each physician's personal acquaintance with the employees under his care. In this type of occupational study the

Table 4 Distribution of subjects according to follow up status

\begin{tabular}{|c|c|c|c|c|}
\hline & Lost to follow up & Resigned or transferred & On sick leave & Retired \\
\hline $\begin{array}{l}\text { Exposed }(1100) \\
\text { Controls }(1100) \\
p\end{array}$ & $\begin{array}{l}24(2 \%) \\
39(4 \%) \\
\text { NS }\end{array}$ & $\begin{array}{l}27(3 \%) \\
25(2 \%) \\
\text { NS }\end{array}$ & $\begin{array}{l}44(4 \%) \\
33(3 \%) \\
\text { NS }\end{array}$ & $\begin{array}{l}155(14 \%) \\
163(15 \%) \\
\text { NS }\end{array}$ \\
\hline
\end{tabular}


Table 5 Causes of death observed during five year follow up period*

\begin{tabular}{lll}
\hline & Exposed (1100) & Controls (1100) \\
\hline All causes: & 20 & 17 \\
Cancer & 9 & 11 \\
Circulatory system & 5 & 3 \\
Cirrhosis & 0 & 2 \\
Trauma & 3 & 1 \\
Others & 3 & 0 \\
\hline
\end{tabular}

*No differences were statistically significant.

exposed group is exposed not only to VCM but also to various other agents with possible pathological effects. To control for these different exposures, the control group included workers whose exposure was similar to that of the exposed subjects, except for VCM. Exposed and non-exposed subjects were not matched by socioeconomic characteristics but the percentage of blue collar workers did not differ between the two groups; moreover an adjustment for this factor was made.

The mean time between the first exposure to VCM and the interview was 18 years. This is important, because a long gap is necessary between exposure and the onset of disease, especially in the case of cancer, which may take eight to ten years to develop.

Most surveys have shown a significant reduction in the mortality of VCM workers as compared with mortality in the general population; this is called the "healthy worker effect."1 7111415 This study, however, as well as other epidemiological studies comparing exposed and non-exposed workers, ${ }^{458}$ found no difference in mortality between the two groups.

Most studies clearly conclude that the target organs for VCM include the liver, the brain, the lung, and probably the lymphohaematopoietic system, the buccal cavity, and the skin (malignant melanoma). Our results are not consistent with those previously reported. In our study no significant association between cancer morbidity and exposure to VCM was observed, and tumours at the following sites were

Table 6 Causes of cancer observed during five year follow up period* (ICD: No 140-209)

\begin{tabular}{lrr}
\hline & Exposed (1100) & Controls (1100) \\
\hline All cancers: & 18 & 15 \\
Lung & 6 & 2 \\
Digestive organs & 5 & 6 \\
Skin & 1 & 1 \\
Buccal cavity-pharynx & 1 & 3 \\
Angiosarcoma of liver & 1 & 0 \\
Pancreas & 0 & 1 \\
Lymphohaematopoietic & 1 & 0 \\
Bone & 1 & 0 \\
Kidney & 1 & 0 \\
Unknown & 1 & 2
\end{tabular}

*No differences were statistically signfiicant.
Table 7 Percentages of circulatory and non-neoplastic respiratory diseases observed during five year follow up period

\begin{tabular}{|c|c|c|c|}
\hline & $\begin{array}{l}\text { Exposed } \\
(1100)\end{array}$ & $\begin{array}{l}\text { Controls } \\
\text { (1100) }\end{array}$ & $p$ \\
\hline $\begin{array}{l}\text { Respiratory system }(460-519) \\
\text { Circulatory system }(390-459) \text { : } \\
\text { Hypertension }(401-405) \\
\text { Coronary insufficiency } \\
(410-414) \\
\text { Cerebral vascular disease } \\
(430-438) \\
\text { Arteriosclerosis of limbs } \\
(4476,4479,4402) \\
\text { Raynaud's disease }(4430) \\
\text { Other circulatory disorders }\end{array}$ & $\begin{array}{r}3 \% \\
10 \% \\
4 \% \\
2 \% \\
1 \% \\
1 \% \\
1 \% \\
2 \%\end{array}$ & $\begin{array}{l}2 \% \\
7 \% \\
3 \% \\
2 \% \\
0 \% \\
\\
1 \% \\
0 \% \\
2 \%\end{array}$ & $\begin{array}{l}\text { NS } \\
0 \cdot 02 \\
\text { NS } \\
\text { NS } \\
\text { NS } \\
\text { NS } \\
0 \cdot 007 \\
\text { NS }\end{array}$ \\
\hline
\end{tabular}

recorded: angiosarcoma of the liver (one exposed), $\vec{\circ}$ skin (one exposed, one control, both epitheliomas), $\underset{\checkmark}{\beth}$ buccal cavity (one exposed, three controls), lympho-

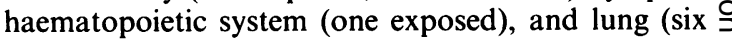
exposed, two controls). Although the number of cases of lung cancer was three times greater in the exposed than in the non-exposed group, the difference was not significant.

In our study a higher percentage of diseases of the circulatory system was observed among the exposed $\infty$ group compared with the controls. This result consistent with others. ${ }^{14711}$ The difference wa explained mainly by the high incidence of Raynauds disease but also by the addition of small differences observed in most of the vascular categories considered, whose physiopathology may be the same as for $\stackrel{\Phi}{\complement}$ Raynaud's disease. A possible relation between $\overrightarrow{\vec{A}}$ exposure to VCM and the occurrence of hypertension 3 or coronary insufficiency has been reported. ${ }^{12} 18$

Although suggested by some authors, ${ }^{316}$ we found no association between exposure to VCM and respi- $\bar{O}$ ratory disease.

We are indebted to: Drs Berrod and Aubrun: RhonePoulenc, 92408 Courbevoie, Dr Pierre: Solvay, 39500 Tavaux, Dr Rety: Atochem, 69190 St Fons, Drs Que- 3 lin and Richard: Rhone-Poulenc Petrochimie, 38150 o Roussillon, Drs Bourrichon, Rambaud, and Bellec: Rhone-Poulenc Centre de Recherches, 93308음 Aubervilliers, Drs Colonne, Cestin, and Bennech: Atochem, 13117 Lavera, Drs Ruty and Lemoine: $\mathbb{N}$ Atochem, 04600 St Auban, Dr Leveque: CDF N Chimie-Usines du Nord, 62160 Bully-les-Mines, Dr N Baylac: Rhone-Poulenc Specialites chimiques, 60170 $\mathrm{\omega}$ Ribecourt, Dr Lussato: Atochem, 13110 Port-deBouc, Dr Barrat: Rhone-Poulenc, 03600 Commentry, Drs Pirot and Favre: Atochem-Balan, $01120 \AA$ Montluel, Dr Puech: Atochem, 38190 Brignoud, and Dr Lazard for their contributions of data. 
Requests for reprints to: Dr Agnès Laplanche, Département de Statistique Médicale, Institut Gustave Roussy, Rue Camille Desmoulins, 94805 Villejuif Cedex, France.

\section{References}

1 Tabershaw IR, Gaffey WR. Mortality study of workers in the manufacture of vinyl chloride and its polymers. $\mathrm{J} \mathrm{Occup} \mathrm{Med}$ 1974:16:509-18.

2 Lilis R, Anderson HA, Nicholson WJ, Daum S, Fischbein AS, Selikoff IJ. Prevalence of disease among vinyl chloride and polyvinyl chloride workers. Ann NY Acad Sci 1975;246:22-41.

3 Miller A, Teirstein AS, Chuang M, Selikoff IJ. Changes in pulmonary function in workers exposed to vinyl chloride and polyvinyl chloride. Ann NY Acad Sci 1975;246:42-52.

4 Nicholson WJ, Cuyler Hammond E, Seidmam H, Selikoff IJ. Mortality experience of a cohort of vinyl chloride - polyvinyl chloride workers. Ann NY Acad Sci 1976;246:225-30.

5 Ott MG, Langner RR, Holder BB. Vinyl chloride exposure in a controlled industrial environment: a long-term mortality experience in 594 employees. Arch Environ Health 1975;30:333-9.

6 Wyatt RH, Kotchen JM, Hochstrasser DL, etal. An epidemiologic study of blood screening tests and illness histories among chemical workers involved in the manufacture of polyvinyl chloride. Ann NY Acad Sci 1975;246:80-7.

7 Fox AJ, Collier PF. Low mortality rates in industrial cohort studies due to selection for work and survival in the industry. $\mathrm{Br} J$ Prev Soc Med 1976;30:225-30.

8 Waxweiler RJ, Stringer W, Wagoner JK, Jones J. Neoplastic risk among workers exposed to vinyl chloride. Ann NY Acad Sci 1976;271:40-8.

9 Brady J, Liberatore F, Harper P, el al. Angiosarcoma of the liver: an epidemiologic survey. JNCI 1977:59:1383-5.

10 Chiazze L, Nichols WE, Wong D. Mortality among employees of PVC fabricators. J Occup Med 1977:19:623-8.
11 Fox AJ, Collier PF. Mortality experience of workers exposed to vinyl chloride monomer in the manufacture of polyvinyl chloride in Great Britain. Br J Ind Med 1977;34:1-10.

12 Waxweiler RJ, Falk H, McMichael A, Mallov JS, Scott Grivas A, Stringer WT. A cross-sectional epidemiological survey of vinyl chloride workers. Cincinnati: Department of Health, Education, and Welfare, 1977. (NIOSH publ No 77-177.)

13 Anderson HA, Snyder J, Lewinson T, Wood C, Lilis R, Selikoff IJ. Levels of CEA among vinyl chloride and polyvinyl chloride exposed workers. Cancer 1978;42:1560-7.

14 Equitable Environmental Health, Inc. Epidemiological study of vinyl chloride workers. (Final report submitted to Manufacturing Chemists Association.) Washington: EEH, 1978.

15 Pierre C, Tassignon JP. Etude de la mortalité chez des travailleurs exposés au chlorure de vinyle. Archives des Maladies Professionnelles, de Médecine du Travail et de Sécurité Sociale 1979;40:1131-45.

16 Theriault G, Allard P. Cancer mortality of a group of Canadian workers exposed to vinyl chloride monomer. J Occup Med 1981;23:671-6.

17 Forman D, Bennett B, Stafford J, Doll R, Exposure to vinyl chloride and angiosarcoma of the liver: a report of register of cases. $\mathrm{Br} J$ Ind Med 1985;42:750-3.

18 Greiser E, Reinl W, Weber H. Vinylchlorid-exposition und mortalitat Deutscher chemiearbeiter im vergleich zur mortalitat nichtexponierter chemiearbeiter und PVC-verarbeiter. Prophylaxe und Ergonomie 1982;32:44-62.

19 Storetvedt Heldaas S, Langard SL, Andersen A. Incidence of cancer among vinyl chloride and polyvinyl chloride workers. $\mathrm{Br} J$ Ind Med 1984;41:25-30.

20 Wartelle M, Kramar A, Jan P, et al. PIGAS: an interactive statistical data base management system. In: Proceedings of the second international workshop on statistical database management Los Altos: Laurence Berkely Laboratory, Statistics Canada, 1983:124-32.

21 Mantel N. Chi-square tests with one degree of freedom: extension of the Mantel-Haenszel procedure. Journal of the American Statistical Association 1963;58:690-700. 